8-1-2011

\title{
Experiential Learning via an Innovative Inter-University IFRS Student Video Competition
}

Mark Holtzblatt

Cleveland State University, m.holtzblatt@csuohio.edu

Follow this and additional works at: https://engagedscholarship.csuohio.edu/bus_facpub

Part of the Accounting Commons

How does access to this work benefit you? Let us know!

\section{Publisher's Statement}

This is an Author's Accepted Manuscript of an article published by Taylor \& Francis Group in Today's CPA, 08-01-2011, available online: http://www.tandfonline.com/.

\section{Original Published Citation}

Holtzblatt, M., \& Tschakert, N. (2011). Experiential Learning via an Innovative Inter-University IFRS Student Video Competition. Accounting Education, 20(4), 349-372. doi:10.1080/09639284.2010.515717

This Article is brought to you for free and open access by the Monte Ahuja College of Business at EngagedScholarship@CSU. It has been accepted for inclusion in Business Faculty Publications by an authorized administrator of EngagedScholarship@CSU. For more information, please contact library.es@csuohio.edu. 


\title{
Experiential Learning via an Innovative Inter-University IFRS Student Video Competition
}

\author{
MARK HOLTZBLATT** and NORBERT TSCHAKERT** \\ ${ }^{*}$ Roosevelt University, USA, ${ }^{* *}$ Salem State University
}

\begin{abstract}
This paper reports on the results of an innovative IFRS Student Video Competition conducted between the author's' universities in the autumn 2009 semester. The competition provided an experiential learning opportunity for 57 graduate level students. A total of 46 recognized accounting standard-setters, partners, professors and other experts were identified, contacted and interviewed. Numerous communication technologies enabled this collaborative venture to connect the expert interviewees to the student interviewers. The end result was the creation of a series of videos on IFRS, each of 10 to 15 minutes in length, available on an educational Vimeo.com channel for the benefit of students and educators worldwide. An expansion of this innovative program to multiple universities throughout the world is possible. In addition, the program and techniques which the authors applied to IFRS pedagogy can be applied to many other emerging accounting topics, especially those that lack traditional teaching resources.
\end{abstract}

KeY Words: Teaching IFRS, IFRS student video competition, IFRS videos, IFRS pedagogy, IFRS interviews, IFRS education

\section{Introduction and Background to the IFRS Student Video Competition}

International Financial Reporting Standards (IFRS) are increasingly being used throughout the world. In 2005, the European Union, and subsequently multiple other countries, began requiring IFRS, primarily for listed entities. In 2010, more than 117 nations either mandate or allow the use of IFRS. In February 2010, the Securities and Exchange Commission (SEC) in the USA published a work plan to support a decision in 2011 towards a potential adoption of IFRS in the USA (SEC, 2010). India, Canada and South Korea are committed to a 2011 implementation date of IFRS.

As a result of these developments, universities worldwide have been looking into ways of exposing their students to the new global standards. At each of our universities we offer

Correspondence Address: Norbert Tschakert, Bertolon School of Business, Salem State University, 352 Lafayette Street, Salem, MA 01970, USA. 
stand-alone IFRS courses at the graduate level. The course materials selected for our classes include traditional pedagogical materials such as books, articles and various publications from the large global accounting firms. We also integrate non-traditional educational materials such as online videos and webcasts dealing with IFRS.

These online videos and webcasts originate from a variety of sources. The main hosts of such media include the global accounting firms, the Canadian Institute of Chartered Accountants (CICA), the American Institute of Certified Public Accountants (AICPA), the SEC, and various universities. In addition, video hosting websites such as YouTube.com, Blinkx.com and Bing.com offer online videos tailored toward the teaching of IFRS.

We observed that the use of these non-traditional pedagogical resources included benefits for both the professor and the students. From the professor's perspective it was now very easy to find expert speakers to address the class. Without extending a formal invitation, or arranging transportation or lodging, or taking a guest out to lunch or dinner, we are able to simply walk into a 'smart' classroom, turn on an internet connected computer and we can instantly expose our students to international accounting experts. From the student's point of view, technological innovations in the classroom such as online videos are much appreciated. In addition, students tend to have a heightened interest in viewing experts in the subject matter. These media may be either shown in class or assigned as homework for individual or group assignments with subsequent class discussion.

However, despite these significant benefits for professors and students there is a drawback to the use of expert webcasts and videos. Students still have the option to be in a passive mode and simply to 'consume' the lecture. By just viewing an IFRS expert discussing the global standards the student absorbs the information but is unable to ask the expert questions or have any interactive or personal communication. Owing to this weakness, we decided to brainstorm and explore new methods to take this non-traditional multi-media resource to the next level.

\section{Transformation to the Next Level of Engagement: Student-created IFRS Videos}

What if a student was not merely a viewer or passive absorber of an online IFRS video or webcast, and instead became a creator or producer of an online IFRS video? That was the question we asked ourselves during the American Accounting Association's Annual Meeting held in New York in August 2009. That moment was the birth of our new Student IFRS Video Project. During the month of August and the early part of September we discussed and drew up the outline of this new student group assignment. The project quickly evolved into an Inter-University Student IFRS Video Competition between our respective graduate classes, even though we were located more than 2,000 miles apart.

Although student video competitions have been conducted in many other disciplines for almost a decade, they are still a new phenomena for Accounting. However, in the past three years several of the global accounting firms have conducted a variety of video competitions.

On 22 January 2008 PricewaterhouseCoopers announced the 'Leadership Adventure Video Contest'. PwC asked undergraduate business students nationwide to answer the question 'What makes a great leader?' Students were encouraged to write, direct and edit their two-minute videos. Videos were accepted between 29 January and 29 February and the winners were announced in April 2008. The five winners each received a $\$ 3000.00$ scholarship and they were invited to attend the 2008 PwC Leadership Adventure, a program for high-achieving college students interested in accounting or information technology careers (PricewaterhouseCoopers LLP, 2008). 
On 12 September 2007, Ernst \& Young LLP announced the launch of a video competition for college students in the USA and Canada as part of the firm's efforts to engage and connect with recruits. The competition, titled 'Reel Influence,' involved more than 75 college campuses. It asked students to create compelling videos around the question, 'Why professional services?' (Ernst \& Young, 2007). The competition created a platform for students to express their creativity, leadership skills, and point-of-view in a public forum, while educating themselves, their peers, and future students about the opportunities available in the field. In March 2008 the three winning teams were announced: they were from York University, Brigham Young University and Fordham University.

Deloitte announced the first Deloitte Film Festival on 10 September 2007 to leverage employee-generated content to bolster Generation Y recruiting activities and drive workforce engagement. More than 370 short films were submitted by teams of Deloitte personnel (one to seven individuals per team), from offices across the world. Over 2,000 Deloitte employees participated. The submitted films were posted on an internal You-Tube-like intranet site where they were viewed and rated by Deloitte's employees. Film production kits, which included a high resolution Panasonic PV-GS 320 Mini DV camera, were offered to the first 250 registrants to encourage maximum participation. Interest and excitement shattered expectations, prompting Deloitte to make an additional 100 cameras available to teams. Cathy Benko, managing Principal of Talent, Deloitte \& Touche USA LLP, said: 'With the explosive growth of social networking sites and the mass democratization of film-making (hand held cameras, user-friendly software), it's very clear to us that the integration of self-expression opportunities through film and other media are essential to recruiting and retaining top talent. Plus it's a heck of a lot of fun!' (Deloitte $\&$ Touche, 2007).

All of these video competitions mostly covered very general and comprehensive topics. They rarely dealt with special fields like accounting and therefore their target seems not to be the conveyance and judgment of knowledge, but rather the exploration of creativity, teamwork, motivation and technical understanding.

While these accounting firm student video competitions and employee film festivals were pioneering and wide in scope, they lacked both academic rigor and coursework integration. The competition/program we have developed fully integrates the video creativity and production aspects of the aforementioned efforts with the requisite educational and professorial aspects expected at the graduate university course level. Appendix 6 shows a student video outline and serves as an example for the academic rigor and supervision involved in this program. In this paper we discuss the pedagogical value of this experiment and want to explore in how far it can be used as an example for teaching IFRS as well as many other emerging accounting topics.

\section{The Components and Guidelines of the IFRS Student Video Competition}

\section{The Student Group Assignment}

For the competition students were assigned to groups of three to four graduates. Each group had its own topic on which to work, although they were all dealing with the issue of IFRS. At one of our universities 33 students were divided into 10 groups. The other university had 24 students divided up into eight groups.

The demanded result of the competition was a video with a length of five to fifteen minutes. The due date of the contest was the 15 December 2009, giving the students exactly three months time for their work.

The student group assignments for both universities consisted of: 
1. Project Management to plan the tasks, responsibilities, and timelines of the group.

2. The creation of an IFRS Video involving expert interviews

3. A PowerPoint presentation

4. An in-class presentation of 2 and 3.

\section{Competition Rules}

A detailed set of competition rules consisting of 12 pages were handed out to all the students at both universities. The detailed rules covered such topics as copyright issues, ownership, release forms for the interviewees, distribution of videos on the internet and helpful resources for creating videos. The rules were written by the supervising professors with consultation provided by various experts and print and online sources. Appendix 4 shows an excerpt of the competition rules used.

\section{Video Recording Equipment}

Each professor provided four complete sets of camcorder equipment to their respective classes. The equipment set included:

1. One Kodak Zi8 camcorder

2. Two Audio Technica Lapel microphones

3. One Radio Shack or Sony table microphone

4. One floor tripod

5. One table tripod

6. One camera bag

7. Accessories such as backup batteries, charger, cables, memory cards, etc.

The complexities of the program were addressed as much as possible beforehand. The equipment was standardized for student groups from both universities to be entry-level and easy to use. Even though the universities had a variety of camcorders available through their ITS Departments, standardization of equipment was deemed important to ensure fairness to all students.

The Kodak Zi8 camcorder which just came out in September 2009 was chosen because it provided several distinct advantages over the competition. It was a blend of High Definition (HD) quality, a low price point, image stabilization and ease of use. Probably the one feature that was most important for us was the Zi8's feature of an external microphone jack that allowed students to use high quality lapel microphones to capture great audio in addition to HD quality video. A lot of online videos lack proper sound quality and the external microphone option sufficiently addresses this issue.

The above mentioned Kodak Zi8 packages were used predominantly for local interviews, held either at our universities or at the local offices of the IFRS experts. In a few cases we shipped camcorder packages to interviewees in order to obtain the highest quality possible while we performed the interview via Skype or telephone conference.

\section{Long Distance Communication Interview Tools}

For most out of state and international interviews we used online communication tools such as the university 'televideo' conferencing or web-based communication software. Section 1 of Appendix 3 includes a description of tools to conduct online interviews. Although the current online conferencing interviewing tools available have evolved 
greatly at this point, it is necessary that the host professor is willing to devote time to test the system and has also planned for a backup solution.

\section{The Video Recording Software}

Most online conferencing tools do not provide a recording functionality which means that this feature has to be added through additional software. Recording proved to be challenging as the software settings as well as a recording check had to be verified upon every single recording. Section 2 of Appendix 3 shows the recording software used in our competition.

\section{The Video Editing and Conversion Software}

Student groups were encouraged to use the Microsoft MovieMaker video editing software which is pre-installed on Windows Vista and Windows 7 based computers. In addition to video editing software, a video converter program was needed because the file created by the Kodak Zi8 is in the .mov format which is read by the Apple Quicktime viewer but is a format not recognized by the MovieMaker program. The Movavi Video Converter program was used to change the videos into a format that could be read and utilized by the MovieMaker program. Students utilizing Apple editing software (iMovie or Final Cut Pro) were able to use directly the .mov files without the conversion. Section 3 of Appendix 3 shows the video editing and conversion tools used during the competition.

\section{The IFRS Expert Interviewees}

During the project management phase of the student video competition, one task the students were confronted with was to identify the relevant IFRS experts on their chosen topic. Internet searches helped the student groups carry out this task. In addition, in some cases the professors had personal connections that were referred to the students to follow-up on. An invaluable resource for some student groups at one university was the cooperation of the Advisory Board of the College of Business, giving this university the upper edge in the competition. The Advisory Board members either directly participated or referred clients or colleagues to help the student groups in identifying potential interviewees.

Once interviewees were identified, the contacting process commenced. To provide support to the students, template email letters were created and distributed. The templates could be customized by the students with the approval of the professor prior to sending to potential interviewees.

One interesting technique for both identifying and contacting potential interviewees involved the use of Linkedin.com, the professional networking website with more than 55 million members globally. Several student groups used linkedin.com to make valuable contacts that resulted in interviews with high profile IFRS experts. Appendix 2 shows the participating interviewees at both universities.

\section{The Student IFRS Video Topics}

We provided a total of 18 IFRS topics that were assigned to 18 groups of three to four graduate students:

1. The SEC Roadmap to IFRS

2. FASB and IASB conceptual framework project 
3. IFRS in Canada and Mexico

4. IFRS for small and medium sized entities (SMEs)

5. Standard setting and political lobbying

6. IFRS and accounting scandals

7. IFRS and International Auditing Standards

8. Non-accounting implications of adopting IFRS

9. IFRS and XBRL

10. IFRS implications for a Southern California based MNC

11. IFRS 'as written by the IASB' versus 'as adopted'

12. IFRS expertise and the employment market

13. Educational implications of the IFRS revolution

14. Valuation under IFRS: Fair value versus historical cost

15. IFRS enforcement issues

16. IFRS implications for a Chicago based MNC

17. IFRS critics

18. IFRS and the implications of LIFO elimination

Appendix 1 shows the detailed description of the topics as provided to our students.

\section{Criteria for Judges in Assigning Prizes}

To provide guidance to students on how their work was to be judged, we developed criteria that were used in evaluating the videos and selecting the winning videos:

1. Correct coverage of assigned IFRS topic

2. Clarity

3. Potential to educate diverse audiences

4. Production quality

5. Creativity

6. Originality

7. Overall impact

\section{Overview of the Student IFRS Videos}

Most of the student-created IFRS videos have reached a very high quality that justifies sharing them online. The videos may be shown in a classroom setting or assigned as homework with subsequent class discussion or related written assignments. The short videos enliven the classroom and make students more attentive as they realize the opportunity to listen to world renowned experts. We have chosen Vimeo over other online video hosting services due to Vimeo's commitment to not-for-profit and original content. Specifically, Vimeo states on its website: 'Vimeo exists to provide you with a space to showcase your creativity and share your life. As such, we do not allow you to upload videos that are commercial in nature or videos that you did not make yourself.' This greatly distinguishes Vimeo from other services such as Youtube.com. In addition, as one of the first online video services, Vimeo offers the opportunity to upload large screen High Definition (HD) videos. Moreover, Vimeo moderates the uploaded videos and the commentary provided by viewers, so that user comments and discussions do not get out of control.

The collection of videos is impressive and opens the door to imagine what is possible with this educational tool in the future. The authors had to solve and overcome significant 
organizational and technical hurdles and faculty and students from different universities joining this competition now will have it a lot easier to really focus on the accounting and educational aspects of the competition. In addition, future technological advances will make this educational tool more and more attractive and feasible.

While all videos have their value, the winning videos give a particularly good introduction to the student-created videos:

1. The SEC Roadmap to IFRS http://www.vimeo.com/8359008

2. Valuation under IFRS: Fair value vs. historical cost http://www.vimeo.com/8415698

3. Educational implications of the IFRS revolution http://www.vimeo.com/8414099

\section{Students' Perspective on the Video Competition}

Questionnaire

To evaluate the students' perception of the video competition, a questionnaire in which the students were surveyed was developed. The questionnaire had two sections in which the students had to mark their assessment on a range from one to six $(1=$ very much; $6=$ not at all). The first section covered the advantages of the video competition, by asking seven questions focusing on the conveyed skills. The overall question was 'How much did the Group Assignment contribute to your expertise in the following areas?' followed by seven possibly conveyed skills:

1. Expertise in the topic

2. Project and self-organizational skills

3. Technological skills and use of online communication

4. Understanding of new social media web sites and technology trends

5. Team working skills

6. Interaction with accounting professionals

7. Preparation for the job market.

The second section consisted of four questions dealing with the discussed challenges of the competition. The four questions were:

1. Did you feel that everyone contributed about the same amount of work to the project?

2. Did you spend too much time on technical and other issues that were not related to accounting?

3. Did you feel motivated during this project?

4. Is the amount of work you put in properly reflected by its contribution to your grade?

Additionally, three open questions were asked:

1. What did you like most about the video competition?

2. What did you like least about the video competition?

3. What are your suggestions regarding improvements for future accounting video competitions? 


\section{Evaluation of Results}

The questionnaire results shown in Table 1 reveal that the most recognized skill is 'interaction with accounting professionals': 33 students felt that they have had 'very much' or 'a lot' of interaction with accounting professionals. When we combine these quantitative findings with the qualitative findings of the question 'What did you like most about the video competition?', it becomes clear that this seemed to be the greatest advantage of the whole project in the students' eyes. This implies that, so far, this opportunity is rarely offered to students during their studies and is at the same time highly welcomed by students.

Looking at the skill 'Expertise in the topic', we see that 29 of the 48 students taking part in the survey declared to have acquired 'very much' or 'a lot' of expertise in the topic to which they were assigned. This implies that a video competition is an adequate exercise for the students to acquire knowledge using learning by doing. However, one cannot assess whether the level of expertise conveyed is equal to or higher than the level of expertise conveyed in a regular accounting class in which the class entirely focuses on the conveyance of knowledge.

Overall the students acquired a large variety of skills during the competition, although some were welcomed more by students than were others. Although the skill 'technological skills and use of online communication' was highly recognized, the skill 'interaction with accounting professionals' was considered to be the most important and valuable by the students when we compare the qualitative and quantitative results. Some of the skills were surprisingly rated lower, such as 'project and self-organizational skills' and 'team working skills', so that one should consider providing the students with more guidance in those fields, enabling students to fully benefit from the potential that this competition offers. It is noteworthy that multiple identified benefits are congruent with the AICPA Core Competency Framework for Entry into the Accounting Profession (AICPA, 1999).

The overall results of the question 'How much did the group assignment contribute to your expertise in the following areas?' are shown in Table 1 below.

\section{Students' assessment of challenges involved in the competition}

Analyzing the students' assessment of the challenges connected to the student video project, we find that the results confirm the prior made assumptions. The questions 'Did you feel that everyone contributed about the same amount of work to the project?' and 'Have you been motivated during the competition?' received an average of 2.60 and 2.88 respectively. One can assess that the students' motivation is highly correlated with the feeling that work is shared in a fair way between group members. This result indicates that free-riding problems were present during the course of the contest. In addition, it

Table 1. Skills learned during the student video competition

\begin{tabular}{lrrrrrrrr}
\hline & 1 & 2 & 3 & 4 & 5 & 6 & $\Sigma$ & Average \\
\hline Expertise in the topic & 12 & 17 & 8 & 4 & 5 & 2 & 48 & 2.56 \\
Project and self-organizational skills & 8 & 11 & 15 & 8 & 4 & 2 & 48 & 2.90 \\
Technological skills and use of online communication & 12 & 11 & 14 & 11 & 0 & 0 & 48 & 2.50 \\
New social media websites and trends & 11 & 7 & 9 & 9 & 5 & 7 & 48 & 3.23 \\
Team working skills & 7 & 17 & 6 & 7 & 6 & 5 & 48 & 3.06 \\
Interaction with accounting professionals & 16 & 17 & 6 & 3 & 4 & 2 & 48 & 2.33 \\
Preparation for job market & 5 & 10 & 11 & 12 & 6 & 4 & 48 & 3.33 \\
\hline
\end{tabular}

$1=$ very much; $6=$ not at all 
might show that the students' motivation is challenged by being in groups, in which not every group member is equally motivated.

The high amount of work caused by the video competition resulted in dissatisfaction concerning the reflection of the work in the students' grades given that $25 \%$ of the final grade was formed by the results of the competition, which students felt was not enough. This feeling is displayed in the students' answer to the question 'Is the amount of work properly reflected by its contribution to your grade?' The average of 3.26 shows that the students would have preferred a higher contribution of the videos results to the grade.

The two major disadvantages as identified by the students are the technical requirements evolving as part of the competition, and the ratio between a student's contribution and his or her final grade.

Table 2 includes a summary of the second section of the questionnaire. Table 2 shows fewer participating students as this feedback form was printed on the reverse side of the questionnaire and some of the students did not notice that the questionnaire included a second page.

\section{Supervising Professors' Perspectives on the Benefits and Challenges of the Video Competition}

During the course of the semester we observed numerous pedagogical and student benefits associated with the student video competition. The following lists display selected benefits that we observed:

- Students learn Project Management and self-organizational skills

- Students have the opportunity to meet with professionals in the industry and discuss accounting issues with them

- Students learn about technological aspects and about using leading-edge online communication tools

- The excitement about video and technology transports over to the classroom and to accounting

- Students learn about new social media websites and trends

- Students have to truly interact with each other and work as a team in order to be successful

The student questionnaire supported our observations as a high percentage of students valued the opportunity to meet with experts. In Chicago, students had the opportunity to visit various partners' offices in order to conduct their interviews. In some cases the

Table 2. Challenges regarding the student video competition

\begin{tabular}{|c|c|c|c|c|c|c|c|c|}
\hline & 1 & 2 & 3 & 4 & 5 & 6 & $\Sigma$ & Average \\
\hline $\begin{array}{l}\text { Did you feel that everyone contributed about the same } \\
\text { amount of work to the project? }\end{array}$ & 16 & 7 & 8 & 4 & 3 & 4 & 42 & 2.60 \\
\hline $\begin{array}{l}\text { In your opinion, did you spend too much time on technical } \\
\text { and other issues that were not related to accounting? }\end{array}$ & 15 & 8 & 6 & 7 & 2 & 3 & 41 & 2.56 \\
\hline Have you been motivated during the competition? & 9 & 10 & 7 & 10 & 5 & 1 & 42 & 2.88 \\
\hline $\begin{array}{l}\text { Is the amount of work properly reflected by its }(25 \%) \\
\text { contribution to your grade? }\end{array}$ & 11 & 6 & 7 & 5 & 5 & 8 & 42 & 3.26 \\
\hline
\end{tabular}

$1=$ very much; $6=$ not at all 
partners, managers or professors visited the university to meet and allow students the opportunity to conduct their interviews. At the other university, greater use was made of the web-based communication technologies to connect students to the experts. The survey results also corroborated that the competition enabled students to increase their knowledge of a variety of technologies and communication methods. Prior to the competition many of the students were not aware of available communication tools such as Skype, Live Messenger or high-end televideo conferencing that are being increasingly used by businesses worldwide. Neither Project Management nor team interaction was as strong a benefit as initially perceived but nevertheless the favorable student ratings were in the majority. The better-performing student groups displayed a high degree of cohesiveness and organizational efficiency from our perspective.

Identified student benefits are:

- Students can include the video project on their resume

- Students can link the video to their Linkedin.com, Spoke.com or other social media account

- All prize-winning group members will receive a letter of acknowledgement from their respective School of Accountancy or College of Business

- Students have the opportunity to win gift certificates to use in their University Book Store

- The project contributes to a good grade in the class $(>25 \%)$

- Students participate in an innovative project that might get significant attention from potential employers

Probably the most challenging aspect of the competition was the amount of time spent on learning and dealing with the technology aspects of filming, converting video formats, and editing. As we have seen, this was a concern mentioned by many of the students surveyed. This can be attributed to the fact that we were learning many of the technologies simultaneously with the students; hence the learning curve was steep for everybody involved. The standardization of camcorder equipment was very helpful, but not sufficient as anticipated by us. Rather, the difficulties stemming from a variety of software tools as well as operating systems (Windows versus Mac) provided for a challenging experience and should have been standardized as well. If we had begun the semester with the required technical knowledge in place, we would have been in a much better position to efficiently impart the necessary skills to the students and provide tighter support. As we mentioned previously, the idea for the competition arose in August 2009, just a month before the autumn semester began, thus we had to learn along the way, together with the students. Looking to future video projects or competitions, we are now in a much better position to provide technical assistance to our students as we have acquired the necessary knowledge and experience regarding the different technologies involved. For professors contemplating a student video assignment we would recommend either becoming familiar with the various technologies and processes in advance of the assignment, or partnering with other experts or departments (i.e. multimedia or information technology services) in the university to support students in performing the necessary technical tasks.

\section{Expansion of the Pilot Project into a Global IFRS Student Video Competition}

Similar to existing business competitions sponsored by global accounting firms, an accounting video competition has the potential to inspire students to excel in certain 
areas and to create a landmark contribution for their career. While the Inter-University IFRS Student Video Competition that we conducted in the autumn 2009 semester involved only two universities, an expansion of such a program to multiple universities in the USA and the world is possible. However, to make such a national or global competition feasible, it may be necessary to reduce the scope of the program to one video per university or one video per course. We are currently discussing an expansion of our pilot program into a global competition.

While the Student Accounting Video Competition described within this paper dealt with the topic of IFRS, there are many other accounting topics that could be fertile areas for conducting student video projects or competitions. The video program is especially useful where there are emerging topics that are not covered (or only weakly covered) by books or articles. Examples in the past have been the Sarbanes Oxley Act, the Accounting Codification and eXtensible Business Reporting Language (XBRL). In addition, the rapidly growing field of forensic accounting would be an excellent topical area for creating student videos. Today accounting is a dynamic field that requires timely adoption of the curriculum and educational resources. Within years the infrastructure for conducting business will undergo fundamental revisions and it will be increasingly difficult for textbooks to stay up to date.

It should be mentioned that, while the video competition we supervised involved interviews with experts in the field, this is by no means a prerequisite. Video projects or competitions could be assigned to students in order to involve the students' own participation, commentary and research without the necessity to interview a local or global expert. Such a project may be more feasible for universities which are located in rural areas without the access to local topical experts.

The authors have developed a set of guidelines and documents for conducting student video programs/competitions which is available to interested faculty.

\section{Conclusion and a Look to the Future of Video as an Experiential Pedagogical Tool}

With emerging technologies it is difficult to project what the future will bring. Online videos, however, have been very successful recently and are now implemented in many business websites. Adobe's flash technology has contributed greatly to this development as it significantly reduced file sizes and the amount of data that needs to be transferred over the internet.

Accounting tends to be a traditional and to some extent conservative field that is not proactively embracing change and challenges as other areas where such changes are more common and accepted (research driven areas like biotechnology or computer science). Introducing a video competition has the potential to make a welcoming difference and to involve and engage students. The rapid technological advancement of just the past few years indicates that video projects in the classroom have a great potential to soon become a valuable pedagogical tool.

As the accounting profession undergoes tremendous changes, academia should explore ways to keep up with these new developments in a timely fashion. Innovative teaching concepts can help to enliven the class and to make accounting more tangible and exciting. By involving students in challenging group assignments, our hope is that students will 'Experience Accounting by Doing'.

The video competition is an innovative approach to teaching international accounting utilizing modern technology and software. The idea for the contest specifically resulted from 
1. the understanding that the currently practiced teaching methodology in accounting is not up to date;

2. the observed lack of academically supervised video competitions that address educational topics on a highly specified level;

3. the opportunity to engage students through the use of technology; and

4. the possibility and goal to interact with accounting professionals from all over the world.

All in all the video competition can be described as successful. All of the groups were able to hand in some results to the professor at the due date of the competition and all of the groups were able to conduct at least two interviews.

The idea of the video competition has potential and should be further explored and developed. Endowing the students with a broad range of different skills as well as contacts to the business world is a move in the right direction.

\section{Selected Student Testimonials}

A creative way to learn a new subject.

We were able to meet interesting accounting professionals.

Interacting with different accounting figures in academia and the practical application side.

Hearing of the viewpoints of professionals and how they varied depending on the position (i.e., academia, consultant, real world, critic, etc.).

The most enjoyment I had was the interaction with the experts. Rarely do we as students or even working students have the opportunity to interact with such esteemed professionals.

I liked that it was difficult. I got to learn about technology that I have not used before. I could be creative with editing and how to perform the interviews.

It was a different, unique and interactive way to learn the course material. Also, encourages the building of relationships with teammates.

\section{Selected Interviewee Testimonials}

Absolutely, what better way than to experientially learn it and this is an experiential opportunity to hear from folks who are expert in IFRS or are teaching IFRS, or becoming more knowledgeable about IFRS. I think you will get a wealth of information that you could not possibly glean from reading it in a manual, you will get a perspective that is not going to jump off the pages. (Marion Powers, Northwestern University, Author and Educator.)

I think it's great for your students, a terrific thing to do and I've learned from it because I do projects in my own class so I do think a video competition, especially among those who participate, is going to be very valuable to them. I do think that video is the way of the future with regard to communication and it is the way of the internet. Video is so powerful if it's done well that I think this is a great project. (Belverd Needles, De Paul University and Vice-PresidentEducation, AAA):

First of all, I love competition and I love creativity and I love when you can put yourself in a learning environment which is not traditional, where you learn by doing it in a different way. That's fantastic. I also like the project because it is giving you the ability to reach out and meet other people and expand your network. (Tim Reierson, Partner, PwC, Chicago.)

We need to make IFRS Education more fun for the students. We want to have students make their own decisions ... the more decisions they can make on their own, the more they will 
learn. We have to prepare these choices for the students ... we need to have a diversity of material. (Salvador Ruiz de Chavez, Vice President, International Association for Accounting Education and Research (IAAER).)

I think this is a great way to kind of expand your classroom. This is a very good set of questions and it reflects good background preparation to understand what the big issues are. (Terry Warfield, University of Wisconsin, Co-Author: Intermediate Accounting.)

\section{References}

AICPA (1999) AICPA Core Competency Framework for Entry into the Accounting Profession (New York, NY, AICPA), Available at http://www.aicpa.org/InterestAreas/AccountingEducation/Resources/Curriculum Development/CoreCompetencyFrameworkar (accessed 5 February 2010).

Deloitte \& Touche (2007) Deloitte Leverages Employee-Generated Short Films to Recruit Gen Y Talent. Press Release, 10 September (New York, NY: Deloitte \& Touche), Available at http://multivu.prnewswire. com/mnr/deloitte/29646/ (accessed 14 January 2010).

Ernst \& Young (2007) Ernst \& Young LLP Launches 'Reel Influence' Campus Video Competition. Press Release, 12 September (New York, NY: Ernst \& Young), Available at http://www.prnewswire.com/.../ernst-young1lp-launches-reel-influence-campus-video-competition-58000022.html (accessed 14 January 2010).

PricewaterhouseCoopers LLP (2008) PricewaterhouseCoopers Announces Leadership Adventure Video Contest. (Press Release, 22 January: New York, NY: PricewaterhouseCoopers LLP). Available at http://www. globenewswire.com/hs/news.html?d=134656 (accessed 15 January 2010).

Securities and Exchange Commission (Washington, D.C.: SEC) (2010) Commission Statement in Support of Convergence and Global Accounting Standards, 24 February. Available at http://sec.gov/rules/other/ 2010/33-9109.pdf (accessed 6 March 2010). 


\section{Appendix 1}

\section{Topics for the IFRS Student Video Competition}

Table A1a.

\begin{tabular}{l}
$\begin{array}{l}\text { Group } \\
\text { no. }\end{array}$ Title and description of topic-University A \\
\hline
\end{tabular}

1 The SEC Roadmap to IFRS

Present and explain the content of the SEC 'Roadmap for the Potential Use of Financial Statements Prepared in Accordance with International Financial Reporting Standards by US Issuers'. Discuss the seven milestones. Discuss Mary Shapiro's position on adopting IFRS in the USA. Focus your work on a discussion of selected comment letters that were due on 30 April 2009. http://www.sec.gov/spotlight/ifrsroadmap.htm FASB and IASB Conceptual Framework Project

'The objective of the Conceptual Framework Project, a joint project of the FASB and IASB, is to develop an improved common conceptual framework that provides a sound foundation for developing future accounting standards.' http://www.fasb.org/ project/conceptual_framework.shtml

During the Conceptual Framework Project, the FASB and IASB discovered that revising the Frameworks is not a trivial task. Describe the scope and importance of this project and focus your work on the many problems involved.

3 IFRS in Canada and Mexico

Explain the rationale behind Canada's (2011) and Mexico's (2012) decision to adopt IFRS. Why did these countries make this decision despite the uncertainty of the events in the USA? How do they benefit from it? What is the current status on the transition? Do companies in Canada or Mexico need more time?

$4 \quad$ IFRS for small and medium sized entities (SMEs)

Provide an overview of the new Standard 'IFRS for Small and Medium-sized Entities (SMEs)' and compare selected accounting rules to IFRS for public companies. Is it attractive to use this standard? What are potential problems? What nations have approved the use of 'IFRS for SMEs' to date? What is the AICPA's perspective on this new standard for US companies? Should additional steps be taken?

$5 \quad$ Standard setting and political lobbying

Explain 'highlights' of the political threats and lobbying that the FASB and the IASB had to go through since their inception. How did the IASB react in each of those incidents? How was this different for the FASB? Has the IASB learned from these events and is the IASB independent for the future as requested in the Roadmap? IFRS and accounting scandals

Briefly present some of the biggest accounting scandals that have occurred throughout the world under US-GAAP and under IFRS. Are these really Accounting Scandals or rather breakdowns of Corporate Governance? Describe what has happened in each case and if the applicable set of accounting standards might have contributed to these scandals. Focus your work on the questions whether IFRS would have made matters worse or better in the particular case under review.

$7 \quad$ IFRS and International Auditing Standards

'The International Auditing and Assurance Standards Board (IAASB) serves the public interest by: setting, independently and under its own authority, high quality standards dealing with auditing, review, other assurance, quality control and related services, and facilitating the convergence of national and international standards.' http://www. ifac.org/IAASB

What is the importance of International Auditing Standards and explain in how far these standards relate to US Auditing Standards. To what extent are International Auditing Standards important for IFRS? Provide an overview of current IAASB projects. 
Table A1a. Continued

\begin{tabular}{ll}
\hline $\begin{array}{l}\text { Group } \\
\text { no. }\end{array}$ & \multicolumn{1}{c}{ Title and description of topic-University A } \\
\hline 8 & Non-accounting implications of adopting IFRS \\
Adopting IFRS is not purely an accounting exercise. For example, consultants \\
frequently advise to also upgrade and harmonize all IT Systems as part of the \\
Transition to IFRS. Is this really necessary? How about implications for HR and Top \\
Management? Show in detail what areas of a company are affected by the transition to \\
IFRS. \\
IFRS and XBRL \\
Extensible Business Reporting Language (XBRL) is understood to have the potential to \\
'revolutionize' business information. Explain how this 'Revolution' would impact \\
Financial Reporting under IFRS. Refer to the IASB Exposure Draft 'IFRS Taxonomy \\
2009'. Show examples of how companies are using XBRL in Financial Reporting. \\
What are problems surrounding XBRL? \\
IFRS implications and experiences for a major Southern California based multinational \\
corporation \\
Identify a multinational Southern California-based corporation and investigate its \\
background and history of global growth. Examine the mention and application of \\
IFRS in its annual report. Potential interviewees include executives in Accounting, \\
Finance, IT and HR. To what extent are they impacted by IFRS and what is their \\
overall view on IFRS?
\end{tabular}

Table A1b.

\begin{tabular}{l} 
Group \\
no. \\
\hline $1 \quad$ 'IFRS as written by the IASB' versus 'IFRS as adopted' \\
Different nuances in IFRS Application around the world are currently a major concern \\
that jeopardizes the comparability of Financial Statements, frequently cited to be the \\
main benefit of Global Accounting Standards. Why have such modifications arisen? \\
Give examples of such nations. \\
IFRS expertise and the employment market impact \\
Research job search websites such as Indeed.com. Survey job descriptions and describe \\
the positions and IFRS related duties that companies are looking for. Contact local \\
executive recruiters for their perspectives. What should students do now to ready \\
themselves for IFRS related careers? \\
Educational implications of the IFRS revolution \\
What is the current status of IFRS education in the USA? Compare the infusion \\
approach (full curriculum integration approach) to the stand-alone approach. Give \\
examples of schools using each approach. What insights into IFRS education progress \\
in the USA is offered by area professors? \\
Valuation under IFRS: Fair value versus historical cost \\
IFRS allows the use of fair value or historical cost valuation for a variety of accounts. \\
Research the various valuation alternatives allowed under IFRS. What are \\
considerations in choosing and implementing a valuation method? Discuss the costs \\
versus benefits in the application of fair value. \\
IFRS enforcement issues
\end{tabular}


Table A1b. Continued

\begin{tabular}{l} 
Group \\
no. \\
\hline \\
The creation of IFRS is only one part of the equation. There is also the question of how \\
to enforce the standards. Research how enforcement of IFRS takes place within \\
various nations. Research the prospects for effective uniform enforcement of IFRS \\
under a global regulatory system rather than the fragmented nationalistic structure \\
currently in place. \\
IFRS implications and experiences for a major Chicago based multinational corporation \\
Identify a multinational Chicago-based corporation and investigate its background and \\
history of global growth. Examine the application of IFRS in its annual report. \\
Potential interviews include executives involved with the Accounting, Finance, HR \\
and Information Technology functions as to the impact and planning related to IFRS. \\
IFRS critics \\
Several prominent regulators, practitioners and professors have been harsh critics of \\
IFRS. Examine the arguments of these IFRS critics and also the negative comments to \\
the Roadmap by respondents that were due 20 April 2009 . Research and discuss the \\
US judicial and legal considerations related to arguments against IFRS in the USA. \\
IFRS and the implications of Lifo elimination in the USA \\
Examine the issues involved in the USA of the potential elimination of Lifo. Interview \\
tax experts in addition to performing background research into this issue. What are the \\
opinions of various US executives of corporations, public accounting firms and \\
government tax authorities and regulators? What are possible solutions to this \\
problem?
\end{tabular}

\section{Appendix 2}

\section{Interviewees Participating in the IFRS Student Video Competition}

\section{(1) Interviewees at University A}

Table A2a.

\begin{tabular}{|c|c|c|c|c|}
\hline No. & First name & Last name & Title/profession & Affiliation \\
\hline 1 & Steve & Austin & Managing Partner & Swenson Advisors \\
\hline 2 & Bob & Colson & $\begin{array}{l}\text { Partner Public Policy and } \\
\text { External Affairs }\end{array}$ & Grant Thornton \\
\hline 3 & David A. & Costello & President and CEO & $\begin{array}{l}\text { National Association of } \\
\text { State Board of } \\
\text { Accountancy (NASBA) }\end{array}$ \\
\hline 4 & Jerry & de St. Paër & $\begin{array}{l}\text { Executive Chairman } \\
\text { GNAIE }\end{array}$ & $\begin{array}{l}\text { IASB Standard Advisory } \\
\text { Council }\end{array}$ \\
\hline 5 & Cindy & Ditman & Partner & BDO \\
\hline 6 & Lee & Duran & Partner & $\mathrm{BDO}$ \\
\hline 7 & Michael & Gibbs & Senior Manager & PwC \\
\hline 8 & Joerg & Grasser & Senior Manager & KPMG \\
\hline 9 & Ian & Hague & Principal & $\begin{array}{l}\text { Canadian Institute Of } \\
\text { Chartered Accountants }\end{array}$ \\
\hline
\end{tabular}


Table A2a. Continued

\begin{tabular}{|c|c|c|c|c|}
\hline No. & First name & Last name & Title/profession & Affiliation \\
\hline 10 & Jeffrey & Hales & Professor & $\begin{array}{l}\text { Georgia Institute of } \\
\text { Technology }\end{array}$ \\
\hline 11 & Bowe & Hansen & Professor & $\begin{array}{l}\text { University of New } \\
\text { Hampshire }\end{array}$ \\
\hline 12 & Gary & Hanson & Partner & $\mathrm{BDO}$ \\
\hline 13 & Steve & Levine & $\mathrm{CMO}$ & Ubmatrix \\
\hline 14 & Jennifer & Matheson & Director Client Services & $\begin{array}{l}\text { Resources Global } \\
\text { Professional }\end{array}$ \\
\hline 15 & Joni & Noel & $\begin{array}{l}\text { Regional Managing } \\
\text { Director }\end{array}$ & $\begin{array}{l}\text { Resources Global } \\
\text { Professional }\end{array}$ \\
\hline 16 & Paul & Pacter & $\begin{array}{l}\text { Director of Standards for } \\
\text { Small and Medium } \\
\text { Sized Entities (SMEs) } \\
\text { at the IASB }\end{array}$ & Deloitte \\
\hline 17 & Felipe & Perez-Cervantes & President & $\begin{array}{l}\text { Mexican Financial } \\
\text { Reporting Standards } \\
\text { Board (MFRSB) }\end{array}$ \\
\hline 18 & Robert & Roussey & Professor & $\begin{array}{l}\text { University of Southern } \\
\text { California }\end{array}$ \\
\hline 19 & Salvador & Ruiz de Chavez & Vice President-at-Large & $\begin{array}{l}\text { Mexican Association of } \\
\text { Accounting and } \\
\text { Business Faculty }\end{array}$ \\
\hline 20 & Heiko & Stueber & $\begin{array}{l}\text { Head of Planning, Budget, } \\
\text { Results }\end{array}$ & Axa Winterthur \\
\hline 21 & Sir David & Tweedie & Chairman & IASB \\
\hline 22 & Rebecca & Villman & $\begin{array}{l}\text { Principal Accounting } \\
\text { Standards }\end{array}$ & $\begin{array}{l}\text { Canadian Institute Of } \\
\text { Chartered Accountants }\end{array}$ \\
\hline 23 & Mike & Willis & Partner & PwC \\
\hline 24 & Jennifer & Yip & Partner & BDO \\
\hline
\end{tabular}

\section{(2) Interviewees at University B}

Table A2b.

\begin{tabular}{|c|c|c|c|c|}
\hline No. & $\begin{array}{l}\text { First } \\
\text { name }\end{array}$ & Last name & Title/profession & Affiliation \\
\hline 1 & David & Albrecht & Professor & Concordia College \\
\hline 2 & Joe & Ament & Professor & Roosevelt University \\
\hline 3 & Vinay & Awati & Director of Accounting Policy & Zurich North America \\
\hline 4 & Jim & Bresingham & $\mathrm{CFO}$ & The Pampered Chef \\
\hline 5 & Jennifer & Cavanaugh & Partner & Grant Thornton \\
\hline 6 & Hans & Christensen & Professor & University of Chicago \\
\hline 7 & Barry & Epstein & $\begin{array}{l}\text { Partner of RNCO, Wiley IFRS } \\
\text { Book Author }\end{array}$ & Russell Novak and Company \\
\hline 8 & Charlie & Flood & Partner & Ernst \& Young \\
\hline 9 & Sue & Haka & $\begin{array}{l}\text { Professor and Past President of } \\
\text { AAA }\end{array}$ & Michigan State University \\
\hline
\end{tabular}


Table A2b. Continued

\begin{tabular}{|c|c|c|c|c|}
\hline No. & $\begin{array}{l}\text { First } \\
\text { name }\end{array}$ & Last name & Title/profession & Affiliation \\
\hline 10 & John & Hepp & Partner & Grant Thornton \\
\hline 11 & Christian & Klein & VP-Public Affairs & $\begin{array}{l}\text { Associated Equipment } \\
\text { Distributors }\end{array}$ \\
\hline 12 & Ken & Kuykendall & $\begin{array}{l}\text { Partner and National IFRS Tax } \\
\text { Leader }\end{array}$ & PwC \\
\hline 13 & Bob & Laffler & Partner & GAAP Seminars \\
\hline 14 & Belverd & Needles & Professor & DePaul University \\
\hline 15 & Charles & Niemeier & Board Member & PCAOB \\
\hline 16 & Bruce & Pounder & President & Leveraged Logic \\
\hline 17 & Marian & Powers & Professor & Northwestern University \\
\hline 18 & Tim & Reierson & Partner & $\mathrm{PwC}$ \\
\hline 19 & Olusean & Salami & Manager & Deloitte \\
\hline 20 & Terry & Warfield & Professor & University of Wisconsin \\
\hline 21 & Lisa & Zambrano & Manager & KPMG \\
\hline 22 & Colleen & Zitt & Corporate Controller & Zurich North America \\
\hline
\end{tabular}

\section{Appendix 3}

\section{Software Tools used during the IFRS Student Video Competition}

Table A3.

\begin{tabular}{|c|c|c|}
\hline Technology/software & Web site & Evaluation \\
\hline \multicolumn{3}{|c|}{ (1) Online interviewing tools } \\
\hline Skype & http://www.skype.com & $\begin{array}{l}\text { Good, proven and reliable tool. } \\
\text { Optimized for Logitech webcams. }\end{array}$ \\
\hline $\begin{array}{l}\text { Windows Live } \\
\text { Messenger }\end{array}$ & $\begin{array}{l}\text { http://www.download.live. } \\
\text { com/messenger }\end{array}$ & $\begin{array}{l}\text { Latest version provide cutting-edge } \\
\text { sound and video quality. }\end{array}$ \\
\hline $\begin{array}{l}\text { Windows Live } \\
\text { Meeting }\end{array}$ & http://www.livemeeting.com & $\begin{array}{l}\text { Very powerful professional tool, } \\
\text { requires monthly fees. }\end{array}$ \\
\hline Wimba & http://www.wimba.com/ & $\begin{array}{l}\text { Sophisticated tool specifically designed } \\
\text { for educational purpose. }\end{array}$ \\
\hline Adobe Connect Pro & $\begin{array}{l}\text { www.adobe.com/products/ } \\
\text { acrobatconnectpro }\end{array}$ & $\begin{array}{c}\text { Professional application. Requires } \\
\text { monthly fees. Fully web-based. }\end{array}$ \\
\hline \multicolumn{3}{|c|}{ (2) Tools for recording online interviews } \\
\hline $\begin{array}{l}\text { TechSmith Camtasia } \\
\text { Studio } 6\end{array}$ & http://www.techsmith.com & $\begin{array}{l}\text { Best Software used during competition. } \\
\text { Very reliable results. } \\
\text { Produces .avi as output file. }\end{array}$ \\
\hline Adobe Captivate & http://www.adobe.com & $\begin{array}{l}\text { Good Software, but uses flash as output } \\
\text { file which is not convenient to } \\
\text { include in video editing with other } \\
\text { formats. }\end{array}$ \\
\hline $\begin{array}{l}\text { Windows Live } \\
\text { Meeting }\end{array}$ & http://www.livemeeting.com & $\begin{array}{l}\text { Very powerful professional tool that } \\
\text { combines online conferencing with } \\
\text { full recording functionality. Requires } \\
\text { monthly fees. }\end{array}$ \\
\hline
\end{tabular}


Table A3. Continued

\begin{tabular}{|c|c|c|}
\hline Technology/software & Web site & Evaluation \\
\hline \multicolumn{3}{|c|}{ (3) Video editing and conversion tools } \\
\hline $\begin{array}{l}\text { Windows Movie } \\
\text { Maker }\end{array}$ & http://www.microsoft.com & $\begin{array}{l}\text { Simple basic editing program that is } \\
\text { included with Windows. }\end{array}$ \\
\hline Apple iMovie & http://www.apple.com/ilife & $\begin{array}{l}\text { Very intuitive editing software for } \\
\text { Apple computers. Included with } \\
\text { Apple computers. }\end{array}$ \\
\hline $\begin{array}{l}\text { AVS4YOU Video } \\
\text { Editor }\end{array}$ & http://www.avs4you.com & $\begin{array}{l}\text { Accompanied by a suite of editing tools } \\
\text { for more advanced functions. }\end{array}$ \\
\hline $\begin{array}{l}\text { Movavi Video } \\
\text { Converter }\end{array}$ & http://www.movavi.com & $\begin{array}{l}\text { An excellent program for the } \\
\text { conversion of .mov to .wmv format. }\end{array}$ \\
\hline
\end{tabular}

\section{Appendix 4}

\section{IFRS Student Video Competition: Competition Rules}

1. All submitted videos must be between 5 and 15 min in length.

2. No profanity, violence, defamatory statements or nudity and no invading the privacy rights of any person or entity.

3. Copyright: It is important that all footage used is original. Participants must have copyright clearance for any music or picture content that they use in their clip. Copyright free music is available on the internet (see 'Helpful Resources' below).

4. You have created the video in collaboration with the students in your group.

5. You specifically did not seek the help of a professional video production service provider.

6. The video has to be narrated in the English language.

7. All interviews should be well-prepared with multiple questions.

8. All videos must be submitted on a CD/DVD and in one of the following formats: .wmv, .mov. or .mpeg. Video Resolution should be $640 \times 480$ or $720 \times 480$.

9. All videos are part of the group assignments and as such are subject to grading.

10. Groups that receive less than full points on their group assignment can still receive an award for their submission to the video competition. Video awards and grading are not necessarily fully related.

11. You will respect the wish of your team member/s should they choose to not prefer a publication of the video group assignment. Specifically, you will not upload or circulate the produced video in any form yourself.

12. The group will thank all participants who contributed to their video in writing and will provide a link to the live video after the completion of the competition. If writing 'thank you' emails, cc your professor.

13. The organizing professors will give teams that have produced videos with errors or questionable content $\mathbf{O N E}$ opportunity to make up these errors and to submit a second revised video. The maximum make-up time is one week and only the final video will be submitted into the competition. The grading for the class will be based on a combination of both, the initial and the revised video.

14. To ensure a high level of quality, the organizing professors have sole discretion in respect to the decision which videos will be considered for online publication as part of the competition. 
15. Videos shall be provided to the judges and uploaded and provided on the Internet by the professors only after they have evaluated the quality of the video and verified that all necessary signatures have been submitted.

16. Every group has to submit a separate and signed 'Competition Rules' Form for each group member.

17. If your team wins one of the awards, you agree to present your video to the class of the competing university in an online conference.

18. Please contact your professor with any questions you might have during the competition.

\section{Appendix 5}

\section{Project Management Homework Assignment}

Homework Assignment: Provide a DETAILED PLAN for your group assignment Deliver your homework assignment until 13 October 2009 (two weeks). Proper Project Management and Communication will be key for the successful accomplishment of your group assignments for this class. This homework intends to help you set the proper foundation for your project.

\section{Submit well-written answers to the following questions:}

(1) Provide a list of material researched on your topic. Provide Hyperlinks where available. You should provide at least 15 to 20 Sources per Topic. Which of these Resources are most valuable to your project? Why? What questions or aspects of your topic do you want to focus on based on your background research into your IFRS topic?

(2) Provide a list of potential interviewees for your topic. Provide a list of potential questions for your potential interviewees. Does your group prefer asking the questions in person, via voice on the video or by creating text slides to be shown preceding interviewee answers or group explanations? Contact at least one potential interviewee and ask for his/her willingness to cooperate using the email draft available on Blackboard.

(3) Are there any graphs, timelines, still pictures, news headlines/stories, statistics, etc. that should be included in your video to provide background information to the viewer? If so, what? How can these materials be incorporated into the video?

(4) Provide a text draft/outline for the video that also describes possible scenes and settings (Office Location at Company xyz, etc.). At this point focus on a very good introduction. Your introduction should make very clear why your topic is important and should make the viewer curious to watch the full video. Provide a timeline with goals that you want to have accomplished by certain dates.

(5) How are duties to be assigned to the group members? Who will ask the questions? Who will focus on the videography, sound aspects and editing? If duties are rotated or shared, how will this be decided? Does any group member have preferences as to the tasks to be performed?

(6) Identify, watch and then share on the discussion board two valuable online videos that teach an aspect of video production and that have not already been cited on the discussion board by other groups. This can be anything from interview tips to proper lightning, voice recording, etc. 
(7) Does your group have access to a backup camcorder or an audio recorder to bring to interviews for multiple-angle shots or in case of equipment malfunction? What is the make and model?

(8) Specify any Questions or Problems you have in respect to the topic or the assignment.

\section{Appendix 6}

\section{Example of a Student-Prepared and Academically Supervised Video Layout: IFRS for Small and Medium-Sized Entities (SMEs)}

\section{Introduction}

As IFRS for SMEs is a new topic, the introduction should be more detailed compared to other topics:

IFRS for SMEs is a self-contained standard, published on July 2009. It is designed to meet the needs of small and medium-sized entities. It is less than 230 pages long and was built on the foundation provided by the conceptual framework of full IFRS, but because it stands alone, it has its own concepts and pervasive principles underlying the financial statements. Many of the principles for recognizing and measuring assets, liabilities, income and expenses have been simplified, topics not relevant to SMEs have been omitted, and the number of disclosures has been significantly reduced. Because it is a self-contained standard, any jurisdiction can adopt it, whether or not they have adopted full IFRS.

US GAAP and IFRS were developed with the equity investors of public companies in mind, so they cover a wide range of issues and require a lot of disclosures that are not necessarily relevant to SMEs.

SMEs are entities that publish general purpose financial statements for external users that do not have public accountability. 'Public accountability' means that the entity's debt or equity instruments are traded in a public market, or that it is in the process of issuing such instruments. An entity also has public accountability if it holds assets in a fiduciary capacity like banks, or credit unions, insurance companies and mutual funds. By that definition, SME is more a comment on the nature of an organization, rather than the size. During its development phase the project was called 'IFRS for private entities', but ultimately the term SME was chosen due to its wide use throughout Europe.

In the USA there are fewer than 20000 public companies but more than 20 million private companies. Worldwide, the IASB estimates that over $95 \%$ of business entities are SMEs. So talking about SMEs means talking about a very large constituency.

\section{Interviews}

The main part of the video will consist of interviews with relevant experts on the topic. We want to capture the first feedback on IFRS for SMEs and want to provide an educated guess on the future of IFRS for SMEs.

\section{Possible interview questions}

1. Can you comment on the current state of IFRS for SMEs today? How has adoption progressed and are there any current developments that are significant to the standard? 
2. What has the feedback been like from the jurisdictions that have adopted or are currently in the process of adopting IFRS for SMEs? Are they finding adoption simple or challenging?

3. Have there been any questions or requests from those jurisdictions currently implementing the standard and has there been a noticeable pattern to the nature of those questions?

4. Are there certain industries that favor this standard? Why?

5. While constructing the standard, what role or function did the IASB see for IFRS for SMEs and is what you are observing now as adoption and implementation proceeds consistent with that vision?

6. Can you comment on the IASB's future plans, goals, or initiatives for IFRS for SMEs?

7. There is currently little or no additional literature or guidance available for IFRS for SMEs. What are the IASB's plans to provide education for IFRS for SMEs?

\section{Confirmed Interviewees}

Lee Duran, Partner, BDO USA.

Andy Ditman, Partner, BDO Canada

Jennifer Yip, Partner, BDO Hong Kong

Gary Hanson, Partner, BDO UK

The different BDO partners will provide a brief impression on their experiences with the SME Standard from different countries. As BDO focuses on medium-sized clients, they are well experienced with the new standard.

Michael Gibbs, Senior Manager, PwC San Diego

PricewaterhouseCoopers in San Diego will provide insight from the client service perspective. Mr Gibbs will be asked questions relating to the amount of interest he gets for IFRS for SMEs; and if there is a thorough understanding about this standard among his client base.

Paul Pacter, Director of Standards for Small and Medium Sized Entities (SMEs) at the IASB.

\section{Conclusion}

We will provide a brief summary and explain that this standard deserves much more recognition from professionals and more coverage from educators as it has the potential to revolutionize accounting and to serve as an important pathway for a quicker worldwide adoption of IFRS.

\section{CONDENSED VIDEO OUTLINE: IFRS for SMES}

I. Introduction: Why is IFRS for SMEs important?

(a) Less than $20 \mathrm{~K}$ public companies in the USA but more than $20 \mathrm{M}$ private companies

(b) An estimated over $95 \%$ of companies worldwide are SMEs

(c) Criticisms of US GAAP

(d) Needs of users of SME financial statements (lender, creditor, owner) often differ from users of public companies.

II. Overview of IFRS for SMEs

a. What is IFRS for SMEs?

1. IFRS for SMEs is a self-contained standard, published on 9 July 2009, of less than 230 pages designed to meet the needs and capabilities of small and 
medium-sized entities which are estimated to account for over $95 \%$ of all companies around the world

2. Define small and medium-sized entity

(b) Current state of IFRS for SMEs

1. Adoption Map

2. UK Consultation Paper issued by Accounting Standards Board in August sets out roadmap for replacing current UK GAAP with a new 3 tier reporting framework based on IFRS

3. AICPA

III. Why should companies adopt IFRS for SMEs? Arguments for adoption.

(a) Addresses the criticism that US GAAP or full IFRS is too complex and burdensome for SMEs, making the standard more relevant and less costly for SMEs

1. A number of topics in full IFRS, not relevant to SMEs have been omitted.

2. Simplified accounting policy choice. In a number of instances where full IFRS provides more than one option, IFRS for SMEs only contains the simpler option.

3. Recognition and measurement simplifications

4. Reduced disclosures - over three quarters of the disclosures in full IFRS have been eliminated

5. Plain English. IFRS principles have been rewritten for clarity and ease of translation

(b) Enhances comparability in global markets

1. Most SMEs have bank loans. Banks (lenders) are one of the major users of SMEs financial statements. Banks operate across borders and want financial information which they can understand and compare

2. Companies buy and sell goods and services across borders. Vendors (creditors) want to evaluate the financial statements of an SME before selling goods or services on credit

3. Credit ratings agencies try to develop ratings uniformly across borders. Development institutions, such as the World Bank and IMF, use financial statements for resource allocation decisions. Accounting differences reduce understandability and obscure comparisons

(c) Enhances information quality and, as a result, overall confidence in the accounts of SMEs.

(d) Reduces the significant costs of maintaining standards on a national basis.

IV. Challenges of adopting IFRS for SMEs.

It should be noted that a lot of the same problems associated with a transition to full IFRS also applies to IFRS for SMEs. Here we have tried, as much as we could, to limit the challenges to issues specific to IFRS for SMEs

(a) Willingness of the users of financial statements to accept IFRS for SMEs.

(b) For companies planning to seek public financing, planning to sell to a public company, or owned by a public company.

(c) Accounting reporting systems will have to be changed or developed to accommodate the requirements of IFRS for SMEs.

(d) Tax planning impact.

V. Addressing the challenges of adopting IFRS for SMEs

(a) As an increasing number of jurisdictions adopt IFRS for SMEs, the application of the principles contained therein will add to the body of knowledge and precedence, giving rise to 'working rules,' or a set of standard practices. These 
working rules will evolve to reflect the different circumstances in different industries and provide the specificity that is currently lacking.

(b) For companies planning to seek public financing planning to sell to a public company, or owned by a pubic company.

(c) Accounting reporting systems will have to be changed or developed to accommodate the requirements of IFRS for SMEs.

(d) Tax planning impact.

VI. What is the general feeling of the industry on IFRS for SMEs and what is the future outlook for the standard?

VII. Closing

(a) Thank audience and interviewee.

(b) Post resources for those interested in researching the topic. 